\title{
Heuristics of Self-Consciousness between Theory of Mind and Intentionality
}

\section{Cristina-Georgiana Voicu}

Romanian Academy, Iaşi, Romania

Email address:

voicucristina2004@yahoo.fr

To cite this article:

Cristina-Georgiana Voicu. Heuristics of Self-Consciousness between Theory of Mind and Intentionality. American Journal of Applied Psychology. Vol. 4, No. 3, 2015, pp. 50-54. doi: 10.11648/j.ajap.20150403.11

\begin{abstract}
This article starts from the interpretation of subjective experience and narrative hermeneutics, suggesting a cognitive re-evaluation of egotic intentionality from the "first-person perspective" and showing together the conjunction between phenomenology and cognitivism (the egotic self). The article also addresses the phenomenal consciousness according to D. Dennett's theory of intentionality. In an attempt to highlight the reflected self as a form of consciousness, the work seeks the continuous updating of the divided self (hyphenated self) and the discovery of a new hybrid self by intercommunication and the awareness of self through "us". Based on the theory of mind, the fluctuations of self and subjectivity aim at revealing the self existence. However, by the need to rethink the self position in relation to the hyper-reality of the mental metabolism, this article explores self-awareness as a new form of intentional dynamics / intentionality.
\end{abstract}

Keywords: Mind, Phenomenal Intentionality, Self-Consciousness, Subjectivity, Heuristics

\section{Introduction}

The issue of the self is one of the most difficult analyzed topics in terms of its definition within the cognitive sciences. Regarding terminology we cannot support the fact that nowadays, a complex and deeply enough theory to capture all aspects of this key concept has been developed. This article is a theoretical approach to self-concept, which aims to highlight its defining strategies through the theory of mind and intentionality.

Based on the heuristic and prospective analysis of the virtual self coupled with consciousness, I will advance towards the direction of a cultural psychology and that permanent removal from the hybridization between real and virtual highlighting the dimensions and heuristic virtues of self-positioning within emerging communities in terms of a so-called self sacrifice to the world's self.

The article addresses both the relationship between intentionality and phenomenology, and the function of the phenomenal consciousness, investigating its role in the mental universe. Through self-consciousness ${ }^{1}$ and moral knowledge of virtual self as an intent of the moral act

1 Self-consciousness is considered as a perception of the self, seen as an object and not as an active subject, which implies an epistemic split towards oneself. manifested in various virtual spaces of convergence, both "ethics" and "practices" of the self oscillates between the structural and phenomenological heuristics ${ }^{2}$ (the conscious experience has itself a phenomenological nature, hence the phenomenal consciousness ${ }^{3}$ ), in this article we try a search for the fundamental aspect of moral and ethical self starting from the theory of intentionality in that the subject attributes himself the mind of an intentional agent - hence the self as an intentional mental agent - distinct from the intentional mental events that take place.

The phenomenal consciousness and intentionality refer to two very general categories, especially to the key aspects of the philosophy of mind. The first relates to subjective representations of experience, and the second shows that the quality of the mental actions focuses on different things or certain objects.

In the first part of the article I will outline two different trends. On the one hand I bring arguments against the notion of separatism, structured under the methodological aspect on the idea according to which the two aspects of the mind are

\footnotetext{
2 Heuristics (when questions are addressed to reasoning) addresses mental rules that generate the emergence of a solution.

3 In this respect, Block argues that there should be a distinction between a phenomenal consciousness and a consciousness that facilitate access to representational content [1]
} 
inseparable, starting from the hypothesis that between intentionality and phenomenal consciousness only a contingent relationship could exist. At the same time, this approach is based on the idea that, although the phenomenal consciousness appears to be a difficult problem by separating its intent, explaining the mind does not encounter major difficulties. On the other hand, the article focuses on approaching the reductive strategies of mental heuristics, as they derive and explain conscious activity in the existence of an intentional framework.

In addition to the two theoretical approaches which form the subject of my criticism, I will choose the third option, which assumes that intentionality has its roots in phenomenology, referring to the fact that while on the one hand the approaches have different meanings, any conscious mental act is considered an intentional one, on the other hand any conscious mental state is based on an undeniable phenomenology, the relationship between the two approaches being not a contingent one.

In this respect, the individual human psyche is highlighted both by the presence of self-consciousness (reflective type) and of the intentionality (external). It is known that the receptors and the moral world and life view grow within consciousness itself. Self-consciousness resides in the ability to produce judgments about the intentions and intentional acts; it is the intuition that a spirit has on perceptions and his actions. Consciousness, as an epiphenomenon of the brain is itself an "intentionality", that is outward.

The concept of intentionality is the one which defines such positioning of the mind (ex. defense and exaggeration of its convictions). Intentionality is a sine qua non of the mind which reflects its orientation and location, definitively and objectively (positioning in an environment with several possible options through which the human individual manages to identify his/her "place" in which his life is placed in a space-time context). Notably, Daniel Dennett's viewpoint considers intentionality as a feature of all forms of intelligence. The so-called egoistic intent is part of the essential structure, defining the self. In a nutshell, this type of positioning to support personal convictions is in fact a mechanism of "cultural survival".

\section{Method}

The purpose of this article is to investigate issues raised by the study of self-consciousness as an intentional process or phenomenon from Daniel C. Dennett's perspective ${ }^{4}$. The first part of the article focuses on an analysis of Daniel Dennett's theory about self-consciousness, the intentionality being a way of relating to understanding the functions of systems (live or designed by humans), starting from the premise that they behave as rational. Being considered the most comprehensive intentional system, the self-consciousness is considered, in this respect, a type of naturally selected

4 In this regard, D. Dennett supports the idea that intentionality can be demonstrated through an adaptive system that rationally manifests itself. behavior because of its ability to monitor a complex system as the human body. The relevant aspects of Dennett's theory of consciousness are the subject of the second part including unifying theories about consciousness and self-consciousness itself as ideo-sphere (phenomenology understood the universe of memes), the theory about intentional states and its criticism. The first part of the article describes the analysis of several bio-philosophical issues relevant to the explored theme according to which the neural correlate of consciousness could be the thalamic-cortical area. The latter occurs in Dennett's study, Consciousness Explained, which is the main source of my analysis in this article, and in which he demonstrates how self-consciousness can be identified with the speech flow inside. With the subjective experience, the self represented by consciousness is an abstraction, an illusion that the brain has created about its capabilities.

The hypothesis from which we started in this article can be exposed as follows: whereas all forms of consciousness are determined by a variety of neuronal processes - thoughts and feelings being nothing else but simple "features of neural system" - self-consciousness - a fundamental concept and element of subjectivity - is, therefore, a cerebral process. In the theory of self existence Searle argues that the "Self (...) is a formal concept; (...) involving the ability to organize intentionality under the constraints of rationality in such a way as to initiate voluntary intentional actions, whose reasons are not sufficient to determine their causality" [my translation] [2]. Hence, the systems of ideas in their logical, cognitive, fractal dimension (which tend to generate infinite solutions according to some simple rules of multiplication, hence the hybrid self) are those forming the self-consciousness.

In this article I address and clarify its conceptual framework, focusing on highlighting, defining and interpreting those two fundamental concepts presented in this article: conscious phenomenology of intentionality. Relying on the basis of intentionality and phenomenology, I made two arguments to support the two meanings / approaches: a) even if the approaches are different, any intentional mental state is conscious, and b) each conscious state is qualitative.

Despite the fact that the qualitative approach is just one of the fundamental properties of consciousness (besides transcendental dynamic flow of self-consciousness), this attribute constituently binds to experience: we can speak of unconscious mental states, but since the conscious state is present, this correlates with the experience of lived sensations, i.e. the subjective ones. When we consider the concept of phenomenology, it is not just about emotions, feelings and sensations, but higher cognitive activities are concerned as far as they are conscious. Moreover, it is not only considered that any conscious experience is qualitative, but also that every conscious experience is considered to be intentional. Beliefs and thoughts not only aim at something, but perceptions, senses and emotions seem to be intentional.

Also, in the second part of the article I sought to distinguish the meaning of the unconscious mind and our conscious (cognitive unconscious, the Freudian unconscious, 
etc.) for the purpose of including other meanings of intentionality, different from those of phenomenal experience. Within this logic, I tried to demonstrate that the approach is too radical starting from the close relationship between phenomenology and intentionality and claiming that intentionality is only possible through phenomenal experience.

\section{Results}

As the philosophy of consciousness regards, there were far different approaches to consciousness in different directions, such as implicit cognition, first person methodology, neural correlates of consciousness, conscious and unconscious neural processes, subjective time, synthesizing, matching problem, quantum approaches, computational theory (self-consciousness allows actions that cross the borders of any computational activity) emerging systems and cultural approaching of the mind.

Except the fact that, in the volume entitled Tratat de morală. După virtute (1998), MacIntyre does not address the concept of hermeneutics when considering itself as a narrative version, claiming that the intentionality of the subject could be considered the first condition giving the self consistency by comparing the ways of interpreting the subjective existence: "We cannot characterize the behavior regardless the intentions and we cannot characterize intentions regardless any frameworks that make these intentions understandable both for agents and for others" [ $m y$ translation] [3]. The second condition of the intentional comprehensibility is given by its positioning in a conversational or narrative context: "Because we all live narration and we understand our life in a narrative key, the narrative form is best suited to understand the others' actions; stories are lived before being told - except fiction" [my translation] [3].

Of major importance in this context is the fact that Paul Ricoeur [4], based on the theoretical model of the action as textuality, examines the relationship between action, motivation and intent, highlighting the essential role of the context. A difficult problem regarding intentionality ${ }^{5}$ is the separation from its consciousness. Starting from the hypothesis that through consciousness ${ }^{6}$ the individual relates to something outside him/herself (transpersonal consciousness), most authors consider the concept of intentionality as an essential feature of self-consciousness.

According to Ricoeur, the hermeneutics and phenomenology guide the self-consciousness towards the most essential coordinate of the reflexive philosophy, given

\footnotetext{
5 Here, the intentions are analyzed as intentions related to tactical asset and active intentions related to strategies.

6 The concept of consciousness which occurs in philosophy of mind bears two meanings: one aimed at self-knowledge as a self-reflection effect of the mind skill (sometimes having to do with an exacerbated self-consciousness) and another that expresses a general feature of cognitive states. In a moral sense, consciousness represents also the ability to consider an action as morally reprehensible or appreciable.
}

that both renounce to an absolute perfect transparency of the self, instead of self-regulation or self-control. Not only phenomenology, seen as a systematic transformation of objective reality, of exposing the joints of the interpreting experience is crucial for Ricoeur's hermeneutics, but especially the concept of intentionality bearing Husserl's profound meaning, according to whom the act of targeting something requires identifiable and re- identifiable unity of the targeted meaning is given the name of intentional correlate of the noetic consciousness. In this respect, the French philosopher considers a non-idealist meaning of Husserl's reductions, without any reference to a transcendental subjectivity, the meaning strongly depending on the concept of intentionality and not necessarily involving the idea of a transcendental subjectivity, the phenomenology bearing a pre-conceived meaning of self-consciousness. Ricoeur's approach of the concept of reductionism is extremely different, namely that form of intentionality of consciousness directed towards a value. Hence, the signification act of intentionality has undoubted importance for Ricoeur. The connection between consciousness and value, i.e. the intentional meaning of noetic acts will cause another problem, that of the hermeneutic circle, the relationship between meaning and intentionality of consciousness itself. Thus, consciousness becomes a way that gives meaning to objective reality in the sense of "opening to something" (intentional behavior).

The theory of mind is a heuristic concept which highlights an essential aspect of the mental metabolism, namely that the subject attributes mental states to others and himself that cause various social events. It can determine social causality and predict intentions in relation to events and contexts, in their reporting to themselves in interpersonal relationships. The concept of "consciousness" is considered a basic concept of mind philosophy as well as those related to self, mental action, perception, emotion, representation ${ }^{7}$, intentionality, subjectivity, thanks to the new emerging paradigm in computational type philosophy (by using artificial intelligence) and cognition. Even if we detach the phenomenal consciousness from the intentionality and cognition - although this act could be considered a fundamental error - it would be impossible to adequately explain cognition, by reference to the neurological processes and computational functionality.

Regarding the "special quality" of self-consciousness, U.T. Place claims in his article entitled Is Consciousness a Brain Process? [5] that consciousness must overlap a model of brain activity only if the subject's insights on the related brain processes can be explained. This was thought as the difference between the experience / subjective consciousness of the first person and neuro-physiological phenomena of the third person between self-consciousness and that regarding the other or the one that exists between conscious and

\footnotetext{
7 The representations are considered as intentional acts, being directed to a reader.
} 
unconscious $^{8}$ mental states. In this case, the many challenges posed by various "theories of consciousness", including that of D. Dennett [7] which sustains that the cognitive systems which have a short memory or the neural networks are considered to be conscious are met.

Currently there is a tendency towards a functionalism of the objective reality that is based on Turing machine ${ }^{9}$ example according to which the computational logic states are actually some mental / computational processes entering the manifestation area of cognitive psychology and artificial intelligence.

I conclude that an intentional relationship has a tertiary size, always involving three different processes: ego / alter ego / ego and alter ego relationship as a real insertion of conscience in the world. Their meaning does not only occur as a match between inside and outside, subject and object, immanent and transcendent, but appears as a participatory relationship in which intentionality exhibits the systematic features of possible relations through some meta-code or meta-social language. The context is one that anticipates intention and directs it by focusing and the subtext chooses the means that will follow as viable alternatives.

Any consciousness involves overcoming a "lived experience" in order to harness the default and relational state between object and subject [8], with a performing emphasis placed on subjectivity. Thus, a touch of intentionality changed in an a priori structural sense via correlation results in. The intentionality of self-consciousness as targeting something appears as a union of a "cogitatum" (intentum) identical with "that thing" which is directed by the intentionality of self-consciousness, the latter being similar to the existence of that process. Hence the functional existence of a "cogito" (intentio) that folds on self-consciousness, but also a life as possible development through knowing the intentionality of self-consciousness. From a phenomenological perspective, self-experiences are actually some intentional feelings, "targeted" to something, and not just some neutral experiences.

\section{Discussion}

Normally, in terms of "rational order", the moral phenomena are "irrational". Ethics as understood ignores morality, thus substituting the responsibility of the moral self under rules that can be taught and direct the accountability to each other and of the moral self-consciousness, a context that resorts to a moral attitude. The moral liability or putting yourself in other's service before being with the other is the

8 Baars [6] develops a theory of global consciousness, according to which the neural basis of consciousness would be an extended reticulo-thalamic activating system. In contrast with the consciousness system that globally manifests, unconscious systems contextually act. Unlike other authors, Baars considers that the second type of system has many essential functions in the nervous system.

9 This type of machine is considered as an ideal technical system or as Searle called it "an abstract mathematical concept" based on two types of values, zero and one, and which operates in compliance with some algorithms. Hence the fuzzy logic which is in fact the self-consciousness logic based on a heuristic reality, whose synthetic expression is given by the subjective mind. first reality of the self that precedes any other cooperation with the other through knowledge, appreciation, suffering or action. The moral responsibility identically reflects the self-constructing process; the failure prompting the shift from the moral self to the social self from being to just to be with.

From a certain point of view intentionality is dependent of consciousness. Through subjectivity the consciously lived actions are inextricably linked to the intentional aspect of mental acts. Thus, the subjective perception of any subject / individual, that feature according to which for example the body appears in a certain way, can be seen as intentionality. On the one hand, between what operates in experience and what is the expertise of experience, there is an indissoluble explanation, whether the intentionality is conscious or unconscious. On the other hand, the approach I have developed in this article reflects a balance of these two extreme positions. However, we cannot ignore that approach according to which although most-intentional mental states have no basis in experience, the representation [9] which is based on the concept of phenomenology must be deprived of its own distinctive characteristics. Because we can talk about several meanings of conscious mental processes we must admit to a certain extent the existence of the unconscious intentionality. Thus, starting from the close relationship between phenomenology and intentionality, I argued in favor of the phenomenal consciousness and mental life representation. Although, we currently do not adequately understand yet the scientific way of causative operating system, however, we have reasons to accept that within the formation of mental life, the phenomenal consciousness plays a fundamental role.

\section{Conclusions}

The conclusions of this article can be structured as such. There is the need for a new structural phenomenological science (transcendental), integrating the levels hierarchy at which self-consciousness can be analyzed (psychological, phenomenological, ethical, etc.) in a complete vision of the self. It is possible that many researchers do not accept the ontological approach on the mind-brain relationship, but such congeries of responses misses a fundamental dilemma: the connection between brain and consciousness. In addition, if a researcher is studying the evolution of the mind and consciousness, this cannot consider them as equivalent: the related brain phenomena responses do not satisfy all the questions about consciousness.

Finally, the methodological conclusion is that we can state that the research ways of self-consciousness suffer from a lack of outcomes integration of its study areas. The study involves unifying consciousness and comparing the findings from several lines of inquiry offering an ontological approach on this. Such an approach belongs especially to philosophy than to the scientific field; philosophy of mind and cognitive sciences are more prepared to appeal to scientific results than the scientific approaches are ready to embrace a philosophical perspective. In this regard, Daniel Dennett's 
view of consciousness highlights extremely well this aspect, his explanations being based on cognitive science and artificial intelligence. However, his theory rather implies a removal of consciousness approaches to the author's own vision not offering too much space to conscious phenomenon. In this respect, I can say that the style of an interdisciplinary approach and the perspective of which the problem of self-consciousness is analyzed make Dennett's view a very appropriate and positive approach to the issues discussed in this article.

\section{Acknowledgement}

This paper is supported by the Sectoral Operational Programme Human Resources Development (SOP HRD), financed from the European Social Fund and by the Romanian Government under the contract number POSDRU/159/1.5/133675.

\section{References}

[1] Block, Ned. "On a confusion about a function of consciousness", Behavioral and Brain Sciences 18, 2/1995, pp. 227-287. Retrieved from http://www.cogsci.soton.ac.uk/bbs/Archive/bbs.block.html on March 1, 2015.
[2] Searle, J. Mintea. Scurtă introducere în filosofia minții, trad. de Iustina Cojocaru, pref. de Adrian Niţă, Editura Herlad, Bucureşti, 2013, p.86.

[3] MacIntyre, A. Tratat de morală. După virtute, trad. de Catrinel Pleşu, Bucureşti: Humanitas, 1998, pp.214, 219.

[4] Ricoeur, P. De la text la acţiune. Eseuri de hermeneutică II, Cluj-Napoca, Editura Echinox, 1999.

[5] Place, U.T. "Is Consciousness a Brain Process?". In Mind, Brains and Computers. The Foudations of Cognitive Science. An Anthology, ed. R. Cummins şi D. Dellarosa Cummins, Oxford, Blackwell Publ., 2000.

[6] Baars, Bernard J. "In the Theater of Consciousness. Global Workspace Theory, A Rigorous Scientific Theory of Consciousness". Journal of Consciousness Studies 4, No. 4. 1997, pp. 292-309. Retrieved from http://www.imprint.co.uk/theatre.htm on April 15, 2015.

[7] Dennett, Daniel C. Consciousness Explained. Back Bay Books/Little, Brown and Company, New York, 1991.

[8] Brentano, Franz: Psychology from an Empirical Standpoint. Routledge, London, 2009.

[9] Jacob, Pierre. What Minds Can Do. Intentionality in a Non-Intentional World. Cambridge University Press, 1997. 